\title{
Cultura corporal: influências das redes sociais virtuais sobre as compreensões de estudantes
}

\author{
Body culture: influences of virtual social networks about the students understanding
}

Cultura corporal: influencias de las redes sociales virtuales en la comprensión de los estudiantes

\author{
FÁbio SOUZA de OLIVEIRA ${ }^{1}$; CLÁUdio MÁrCIO OLIVEIRA ${ }^{2}$ \\ Secretaria de EducaÇão do Estado da Bahia, SEE-BA, Feira de Santana-BA, Brasil \\ UniVERSIDAde Federal de Minas Gerais, UFMG, Belo Horizonte-MG, BraSIL
}

\begin{abstract}
RESUMO
O presente estudo teve como objetivo analisar as possíveis influências das redes sociais sobre as compreensões dos estudantes da educação básica a respeito dos elementos da cultura corporal. Participaram da pesquisa cento e vinte e oito alunos do ensino fundamental II, de uma escola pública estadual da cidade de Feira de Santana. Verificamos neste estudo a presença de um modelo de voleibol que foi instituído antes mesmo do tratamento pedagógico do voleibol na escola, o voleibol midiático, de alto rendimento. Conclui-se que, através da abordagem mídia-educativa, é possível propor resistência às construções fragmentadas propostas pelas mídias, particularmente pelas redes sociais virtuais, a respeito dos elementos da Educação Física.
\end{abstract}

Palavras-chave: Mídia-Educação. Educação Física Escolar. Redes Sociais Virtuais.

\begin{abstract}
This study aimed to analyze the possible influences of social networks about the Basic Education students understanding regarding the elements of body culture. One hundred twenty-eight elementary school students from a state public school in the city of Feira de Santana participated in the research. In this study, we verified the presence of a volleyball model that was instituted even before the pedagogical treatment of volleyball at school, high-performance media volleyball. It was concluded that, through the media-educational approach, it is possible to propose resistance to the fragmented constructions proposed by the media, particularly through virtual social networks, regarding the elements of Physical Education.
\end{abstract}

Keywords: Media-Education. School Physical Education. Virtual Social Networks.

\section{RESUMEN}

Este estudio tuvo como objetivo analizar las posibles influencias de las redes sociales en la comprensión de los estudiantes de Educación Básica con respecto a los elementos de la cultura corporal. Ciento veintiocho estudiantes de primaria de una escuela pública estatal en la ciudad de Feira de Santana participaron en la investigación. En este estudio, verificamos la presencia de un modelo de voleibol que se instituyó incluso antes del tratamiento pedagógico del voleibol en la escuela, voleibol mediático de alto rendimiento. Concluimos que, a través del enfoque mediático-educativo, es posible proponer resistencia a las construcciones fragmentadas propuestas por los medios, particularmente a través de redes sociales virtuales, con respecto a los elementos de la Educación Física.

Palabras clave: Média-Educación. Educación Física Escolar. Redes Sociales Virtuales.

\footnotetext{
1 Mestre em Educação Física Escolar (PROEF/UFMG) e professor da SEE-BA. E-mail: fabiopatchanka@ hotmail.com. ORCID: http://orcid.org/0000-0002-7584-6591.

2 Professor Adjunto do Departamento de Métodos e Técnicas de Ensino da UFMG. E-mail: clamoliv1974@hotmail.com. ORCID: https://orcid.org/0000-0002-8677-6269.
} 


\section{INTRODUÇÃO ${ }^{3}$}

O crescimento dos aparatos tecnológicos é uma situação consolidada na sociedade contemporânea, o que significa dizer que os mais diversos segmentos e instituições sociais são atravessados pelas tecnologias digitais de informação e comunicação (TDIC), e mais especificamente, por aquelas denominadas tecnologias móveis, que tem maior relevância neste cenário por estarem cada vez mais perto e disponíveis para os indivíduos, na maioria das vezes, dentro do próprio bolso. Como consequência dos processos que transformaram os dispositivos digitais e a internet no meio de comunicação por excelência, está o nascimento das redes sociais (AMENDOLA; GIGLI; MONTI, 2018). Neste sentido, a escola, como instituição na e da sociedade, também é afetada pelos efeitos destas tecnologias e podemos perceber em seus diversos atores, o uso crescente destes dispositivos, de modo particular o telefone celular smartphone e o acesso às redes sociais virtuais.

Apesar do seu inegável potencial como instrumentos formativos, paradoxalmente, vários são os problemas decorrentes da presença das tecnologias na escola hoje. Para Gimeno Sacristán e Pérez Gómez (1998), as TDIC, oferecem de modo atrativo, grande acervo de informações sobre os mais variados aspectos da vida, criando sobretudo nas crianças, concepções ideológicas que elas utilizam para interpretar o mundo. Este mesmo problema, como tantos outros, reflete também na Educação Física, pelas produções midiáticas relacionadas aos elementos que compõem este componente curricular. Elas (as TIDC) oferecem aos estudantes, a maior parte das representações que eles dispõem sobre as danças, os jogos, os esportes e os demais elementos da Educação Física.

Assim, a relação entre as mídias e a Educação Física escolar se esboça como uma das grandes problemáticas desta área, e compreender como estas realidades se interrelacionam é uma das estratégias docentes no sentido de fazer formação em Educação Física escolar. Por outro lado, apesar do uso cotidiano do celular multifuncional e, portanto, da facilidade no manejo deste dispositivo, os alunos da educação básica, reproduzem cada vez mais o seu uso pessoal/doméstico na escola: envio de mensagens textuais ou audiovisuais, recebimento e envio de chamadas de voz, fotografias, principalmente as popularmente conhecidas como "selfies" e acesso às redes sociais. Além disso, os estudantes deste segmento educacional se valem destas mesmas redes sociais para a prática de bullying e até mesmo pequenos atos infracionais.

Este artigo é decorrente da dissertação de mestrado apresentada ao Programa de Mestrado Profissional em Educação Física (PROEF), e teve como objetivo central, analisar as possíveis influências das redes sociais sobre as compreensões dos estudantes da educação básica a respeito dos elementos da cultura corporal, como os jogos, os esportes, as danças e as ginásticas atividades expressivas corporais tematizadas pela Educação Física escolar (SOARES et al., 2009).

\section{Procedimentos Metodológicos}

Situamos a metodologia deste estudo no campo da Pesquisa Social, que para Minayo (2014, p. 47) são "[...] os vários tipos de investigação que tratam do ser humano em sociedade, de suas relações e instituições, de sua história e de sua produção simbólica". Sua abordagem é compreendida como essencialmente qualitativa por se

\footnotetext{
${ }^{3}$ A dissertação que deu origem a este artigo foi financiada pela Coordenação de Aperfeiçoamento de Pessoal de Nível Superior (CAPES).
} 
ocupar dentro das Ciências Sociais, "[...] com o universo dos significados, dos motivos, das aspirações, das crenças, dos valores e das atitudes" (MINAYO, 2016, p. 20).

O campo empírico desta pesquisa foi um colégio da rede estadual de ensino de Feira de Santana, cidade do interior do Estado da Bahia. A escolha desta unidade escolar se deu por ser local de atuação docente do pesquisador, de onde emanaram as questões envolvendo o uso do aparelho celular. $\mathrm{O}$ acesso e a liberdade para a realização da pesquisa foram fatores decisivos para a tomada desta decisão.

O universo deste estudo foram os estudantes dos oitavos e nonos anos deste colégio, com idade entre treze e dezessete anos, por ser a faixa da juventude mais atingida pelos conteúdos midiáticos através do smartphone (MÜLLER, 2019). Foram ao todo 4 salas com média de 32 alunos cada, totalizando 128 estudantes. Cientes da riqueza de informações do campo de estudo, lançamos mão de diferentes técnicas de interlocução como o questionário, a entrevista, a observação participante e o diário de campo. Para Minayo (2014, p. 189), é através dos instrumentos de pesquisa que poderemos "[...] fazer a mediação entre os marcos teórico-metodológicos e a realidade empírica".

A observação participante e o diário de campo são as técnicas que permitem as primeiras aproximações com o campo empírico, revelando-nos suas verdades e permitindo juntar o que estava se fazendo intelectualmente e o que se estava experimentando como pessoa (MILLS, 1972).

O questionário foi utilizado como instrumento de avaliação diagnóstica nas salas de aula e um dos seus objetivos foi mapear o uso do smartphone entre os pesquisados e, de interesse particular para este recorte, o uso das redes sociais por estes estudantes.

A entrevista do tipo aberta, por sua vez, foi utilizada no sentido de verticalizar o mapeamento iniciado com o questionário, permitindo a obtenção de informações mais aprofundadas, facilitando a compreensão dos fenômenos e subsidiando outras discussões durante as aulas. Para Minayo (2014) a entrevista aberta é aquela em que o informante é convidado a falar livremente sobre um tema e as perguntas do investigador, quando feitas, buscam dar mais profundidade às reflexões. Considerando que a relevância das entrevistas estava nas falas dos interlocutores que dariam forma a uma lógica própria do grupo, "escolhemos" dentre todos os participantes do estudo, oito estudantes: quatro que possuíam celulares e quatro que não os possuíam. A investigação no campo empírico durou um trimestre letivo, período em que também foram realizadas intervenções com o conteúdo voleibol.

Estabelecidas as estratégias de diálogo com o campo empírico, cumpre esclarecer como realizamos suas análises. Nos inspiramos na "Triangulação de Perspectivas", proposta por Minayo (2014), combinando dados do diário de campo, do questionário e das entrevistas, favorecendo a qualidade e a profundidade das análises, multiplicando as tentativas de aproximação. Desta forma, os dados foram analisados quantitativa e qualitativamente, em diálogo permanente com a literatura pesquisada.

Finalmente, convém ressaltar que os responsáveis e os estudantes que participaram deste estudo leram e assinaram o Termo de Consentimento Livre e Esclarecido (TCLE) e o Termo de Assentimento Livre e Esclarecido (TALE), apreciados e aprovados pelo Comitê de Ética em Pesquisa (CEP) da instituição envolvida sob a identificação CAAE: 22800619.0.0000.5149 e parecer número 3.827.841. 


\section{AS REDES SOCIAIS DE INTERCÂMBIO}

Em tempos de tecnologias digitais, os estímulos audiovisuais que afetam crianças e adolescentes em idade escolar são crescentes e na contramão desta realidade, a forma como os conhecimentos são apresentados na escola parecem insossos, em comparação com aqueles das demais possibilidades oferecidas fora da sala de aula: o bate-papo no pátio, o jogo de bola na quadra, as risadas dos colegas, o sambinha improvisado nas carteiras. Essas "atratividades" cotidianas, por sua vez, parecem pouco competentes para concorrer com as telinhas dos dispositivos digitais: berrantes, cintilantes, excitantes. Em outras palavras, os estímulos do ambiente do dia a dia, assim como aqueles do meio escolar formal, parecem não ser páreo para aqueles apresentados pelas mídias digitais. Os primeiros, "[...] representam estímulos de menos para serem percebidos" (TÜRCKE, 2010, p. 66).

Pucci et al. (2016, p. 20), a este respeito diz que, "[...] cada corte de imagem atua como golpe óptico que irradia para o espectador um "alto lá", "preste atenção", "olhe para cá" e aplica uma pequena nova injeção de atenção, uma descarga mínima de adrenalina". Diante de tantos estímulos, o que toca, o que atinge cada indivíduo, ou melhor, o que chama a atenção é aquilo que for agudizante o suficiente para o sistema nervoso, ainda que por um pequeno instante. Türcke (2010), já previa o papel dos meios audiovisuais nos dias atuais, que pudessem atingir os canais sensoriais ultrassaturados dos indivíduos de hoje, como uma injeção multissensorial.

São estas telinhas das TDIC, particularmente o celular smartphone, que por suas características abrem espaço para acesso à informação ilimitada, nas mais variadas formas e cores, disputando a atenção de contingentes sempre maiores. Segundo o IBGE (2017) o celular está presente na vida de quase $70 \%$ dos estudantes brasileiros. De acordo com este órgão, no mesmo período, 97\% dos brasileiros acessaram a internet a partir de um aparelho celular. Deste modo, o celular é o principal dispositivo de acesso à internet e, portanto, aos sites e redes sociais, onde está a maior parte do conhecimento que pode dar origem ao saber (MARTÍN-BARBERO, 2014).

Para Dias e Couto (2011) as redes sociais são ambientes virtuais nos quais sujeitos se relacionam e estabelecem meios para formulação e circulação do conhecimento. Sua popularidade, sobretudo em meio aos adolescentes, deve-se a uma série de fatores como a possibilidade de estarem sempre conectados com os próprios grupos de pertencimento, permanecerem informados sobre os assuntos que lhes interessam, fazer novas amizades ou mesmo com fins de entretenimento, como escutar músicas, assistir vídeos e para jogar (AMENDOLA; GIGLI; MONTI, 2018). De fato, as primeiras redes sociais não obtiveram tanto sucesso. Foi a partir de 2004, com a criação do Facebook, especificamente projetado para universitários, que verificamos a crescente e maciça adesão às redes virtuais de intercâmbio, atraindo grandes investimentos econômicos e ampliando suas possibilidades para o campo das informações e de serviços (AMENDOLA; GIGLI; MONTI, 2018). Impulsionadas, sobretudo pelos grandes lucros, as redes sociais trazem no bojo condições antagônicas às suas aparentes vantagens com a difusão das fake news, os casos de cyberbullying, a violação de dados dos perfis de usuários, sem mencionar as possíveis reverberações das relações virtuais no campo afetivo (AMENDOLA; GIGLI; MONTI, 2018). Apesar de sua ambígua condição, as redes sociais evoluíram e evoluem a ponto de atenderem demandas específicas de cada público. Dentre as mais acessadas atualmente estão aquelas que possuem notoriedade global a exemplo do Facebook, Instagram, Snapchat, Spotify, Tumblr, Twitter e o WhatsApp. Para os adolescentes, por exemplo, já é possível escolher aquelas que são menos frequentadas pelos adultos, usufruindo de maior liberdade e autonomia. Além 
disso, outro grande diferencial buscado nas redes sociais é o aumento do capital social (RECUERO, 2018). Para a autora, as redes sociais permitem o aumento significativo das conexões sociais, da visibilidade, construção da reputação, popularidade e até mesmo o reconhecimento enquanto autoridade num dado campo.

Na compreensão de Gimeno Sacristán e Pérez Gómez (1998), as redes sociais de intercâmbio de informação, ao destilar sutilmente a ideologia dominante nas representações de mundo dos estudantes, deixam para a escola a função de facilitar o desenvolvimento da compreensão, a reconstrução crítica do conhecimento do mundo, formando, portanto, para a autonomia. Deste modo, os alunos já chegam às escolas, cada vez mais munidos de uma série de informações, disponíveis nos sites e redes sociais, acessadas principalmente através do celular.

Por conseguinte, Souza e Mendes (2014) destacam as representações propostas pelas mídias sobre a cultura corporal de movimento, base dos conteúdos da Educação Física. Para estes mesmos autores, os esportes, as danças, as lutas, as ginásticas, são apropriados pelas mídias e expostos de forma espetacularizada à população em geral, influência que acaba por empobrecer a concepção dos estudantes em relação a esta área.

Pires (2002), ao tratar das formas como as diversas mídias manipulam os elementos do campo da Educação Física diz que importa compreendê-las criticamente, verificando "[...] as implicações diretas e indiretas da apropriação da cultura de movimento e esportiva pelo sistema informacional, a fim de perspectivar possibilidades de intervenção da área, voltada a um projeto de construção social da cidadania emancipada" (p. 56).

Considerando a forma como os elementos da cultura corporal são apropriados pelas mídias e compreendendo a necessidade de formar pessoas capazes de lidar criticamente com o discurso midiático, não é suficiente que a educação midiática se atenha a aspectos operacionais, sobre como lidar com as TDIC e como utilizar as redes sociais virtuais. Neste sentido destacamos a abordagem mídia-educativa, que para Fantin e Rivoltella (2012) é entendida como a possibilidade de educar para/sobre as mídias, com as mídias e através das mídias, a partir de uma abordagem crítica, instrumental e expressivo-produtiva. Para a autora, educar para as mídias é tornar os estudantes capazes de compreender, interpretar e avaliar os conteúdos das diversas mídias. Educar com as mídias inscreve-se no âmbito da didática, valendo-se das tecnologias digitais como recurso didático, inserindo novas possibilidades de educar com estes recursos, numa perspectiva instrumental. E, educar através das mídias significa utilizar as mídias como linguagem, como forma de expressão e produção. É a partir deste prisma que buscamos compreender as possíveis influências das redes sociais sobre os elementos da cultura corporal.

\section{RESULTADOS E DISCUSSÕES}

O fio das discussões aqui apresentadas será tecido com base no diálogo entre os diferentes instrumentos desta pesquisa, buscando estabelecer relações com os autores apresentados. Intentamos compor uma "imagem" que nos faça vislumbrar mais apropriadamente quais apropriações os estudantes fazem das redes sociais virtuais.

Antes, porém, de tratarmos do uso das redes sociais pelos estudantes deste estudo, é importante situá-las no contexto atual. Nesta pesquisa, identificamos que nove em cada dez estudantes acessa internet diariamente e o tempo médio diário de uso é superior a cinco horas. Este tempo é superior àquele destinado à escolarização formal na maioria das unidades escolares do país, o que significa dizer que estes estudantes estão 
expostos a um volume de informações que, em tese, é maior do que o que a escola pode problematizar. A internet se configura como um poderoso portal de acesso a um sem fim de informações que, de forma irrefletida, auxiliarão na construção de representações sociais que estão, em grande medida, distorcidas, permeadas por ideologias, manipulações, posicionamentos políticos, religiosos, dentre outros. A compreensão e apropriação didático-pedagógica deste recurso podem ajudar a construir um percurso formativo em direção à autonomia e à emancipação.

O principal dispositivo utilizado para acesso à internet por estes estudantes é o telefone celular (81\%), número superior àqueles identificados pelo IBGE (2017). Com base nestas informações, podemos, concordando com o IBGE, dizer que o celular é a mídia digital mais disponível e mais utilizada para acesso à internet no Brasil atualmente, compondo importante instrumento de pesquisa e de acesso à produção cultural.

Foi identificado que o $86 \%$ dos estudantes possuem um smartphone, configurando a tecnologia de informação e comunicação mais disponível da atualidade. A partir deste dado podemos estabelecer estratégias docentes pautadas na abordagem mídia-educativa, sobretudo se considerarmos que os estudantes acessam as informações disponíveis na internet a partir deste dispositivo e de interesse particular deste estudo, destacadamente as que estão nas redes sociais virtuais. Além disso, podemos pensar dialeticamente de que forma o celular e o acesso às redes sociais podem estar sendo impeditivos de aprendizagem efetiva, dado o alto número de horas dedicado a seu uso.

A partir do questionário, identificamos que nove em cada dez alunos utiliza algum tipo de rede social virtual, dado que pode ser bastante explorado em propostas mídiaeducativas. Primeiro porque parte significativa do tempo dedicado à internet $\mathrm{e}$ ao uso do celular é utilizada com estas redes. O conteúdo que transita nestas comunidades é, portanto, relevante para uma proposta educacional que se ocupe das tecnologias digitais, uma vez que os acessos já são verificados mesmo por crianças que ainda são foram alfabetizadas. Além disso, os algoritmos envolvidos na investigação de perfis de usuários, potenciais consumidores de qualquer produto que possa ser vendido, diversas vezes se valem destas redes para pulverizar suas publicidades após estudo de tendências destes perfis, o que comumente passa despercebido pelos adolescentes usuários destas redes. Além disso, o trato com o conhecimento pautado nas mídias requer atenção também às questões de ubiquidade, de como as mídias estão sendo programadas para "lerem" nossas necessidades e nos oferecerem, justo aquilo que precisamos, como uma solução milagrosa às nossas demandas. Estes são apenas alguns dos exemplos do que propõe a chamada "indústria cultural" (ADORNO, 2002).

Atualmente há uma ampla gama de redes sociais, atendendo a diferentes propósitos e agrupando, portanto, aqueles que se interessam determinado conjunto de informações. A respeito das redes sociais mais utilizadas, constatamos neste estudo uma tendência já percebida empiricamente. O WhatsApp, o Instagram e o Facebook são as três redes sociais virtuais mais utilizadas pelos alunos. Uma parcela menor utiliza também o Twitter e o Tinder. Cada uma destas redes mereceria uma análise à parte, por contemplarem propósitos que distam entre si. Dadas as limitações impostas pelas dimensões deste estudo, nossas considerações serão de ordem genérica.

Conforme mencionam Dias e Couto (2011), uma das importantes premissas das redes sociais é a troca de informações. Então, um primeiro questionamento que pode balizar os olhares formativos seria, quais informações são buscadas ou ofertadas em cada uma destas redes? Considerando a dimensão crítica da abordagem mídia-educativa há uma série de questionamentos que se desdobram deste, permitindo refletir e desvelar aspectos que estão velados, ou ainda aqueles explícitos, mas que não são comumente 
problematizados. Alguns destes conteúdos, constatamos neste estudo, são de apelo sexual ou violentos.

Apesar de não termos encontrado postagens em redes sociais como o Facebook e o Instagram sobre conteúdo violento entre os alunos, identificamos em algumas situações durante o tempo da pesquisa que, discussões, brigas e outros acontecimentos envolvendo violência na escola são merecedores de grande atenção entre eles, entretanto, este conteúdo é mais compartilhado por WhatsApp, não ficando disponível nas páginas pessoais. Outros conteúdos têm caráter formativo, a exemplo de vídeos e informações sobre profissões e os estudantes têm feito uso autônomo destas possibilidades. Compreendemos que cabe à escola, em primeiro plano, discutir com seus atores estes conteúdos, mantendo no horizonte as premissas de processos educacionais atentos à formação (ADORNO, 1995).

Além disso, parte considerável do tempo de navegação nas redes sociais virtuais pelos estudantes é investido em acompanhar postagens das próprias conexões sociais virtuais ou fazendo novas postagens. Türcke (2010), já tratava desta aparentemente necessária constante emissão de estímulos, como parte do ser, do existir. Para o autor "[...] quem não chama a atenção constantemente para si, quem não causa uma sensação, corre o risco de não ser percebido" (p. 37). Demanda tempo para ver e ouvir o que está na própria rede social virtual, às vezes, nas próprias redes sociais, pluralmente falando. Claramente um primeiro questionamento que se impõe é: qual o produto deste investimento? Esta resposta pode ser construída na escola. Ademais, como eles se percebem neste contexto de produção digital como condição para serem percebidos?

Do ponto de vista da Educação Física, registramos em diário de campo, uma série de postagens que expõem corpos em posições ou movimentos erotizados. Posições que valorizem curvas corporais, que exponham partes desnudas do corpo e que tenham apelo sexual, agudizando o aparato sensorial, como dizia Türcke (2010), tem alto valor no universo das curtidas, possivelmente direcionando as postagens. Alguns destes movimentos são inclusive nominados, a exemplo da já popular "sarrada", expressão utilizada para uma gesticulação corporal que mimetiza um ato sexual. Em última análise, o comportamento dos protagonistas é moldado também pela sua audiência, através deste meio técnico. O mesmo raciocínio se aplica aos vídeos, com um adendo: não podem ser longos. Quanto mais longo, mas difícil de manter a atenção dos seus expectadores. Recuero (2018), ao analisar as características das redes sociais, identificou características que coadunam com estes dados. As postagens em redes sociais buscam consolidar ou mesmo ampliar o capital social de cada perfil, de cada estudante. Assim, estar atento às demandas das suas conexões é um importante passo para aumentar sua visibilidade, número de conexões, popularidade, dentre outros.

Algumas redes sociais, sobretudo as do tipo podcasts, proporcionam os hits que alicerçam algumas destas manifestações corporais. O repertório é na maioria das vezes, funk, rap e pagode. As letras, ouvimos nos corredores, nas salas de aula, no pátio, através das potentes caixas de som conectadas via bluetooth, tratam de violência ou sexo, com raras exceções, permeando as postagens do Instagram $^{4}$ e do Facebook, como pano de fundo para fotos pessoais. Deste modo, não podemos nos furtar ao questionamento sobre quais as possíveis influências dos conteúdos midiáticos sobre os gostos dos alunos por estes gêneros musicais e como estes podem influenciar o movimentar dessa juventude. As letras e danças destas músicas, tão presentes no meio destes, podem ser coadjuvantes nos processos de naturalização da violência e do sexo entre eles? No contexto da Educação Física, quais as possibilidades no que tange à

\footnotetext{
${ }^{4}$ As relações estabelecidas com parte significativa dos alunos preveem a aceitação recíproca nas redes sociais virtuais.
} 
crítica sobre letras e danças com tais conteúdos? Quais outras possibilidades de se movimentar são possíveis com estes ritmos?

Dentre os recursos mais utilizados no smartphone e que possui relação estreita com a utilização das redes sociais por estes estudantes, está o uso das fotografias, certamente pela grande facilidade de se produzir e postar estas imagens em suas páginas virtuais, o que parece ser o seu objetivo maior. Eles registram tudo e talvez por naturalização desta ação ou por outro motivo que não identificamos, as fotos não foram o principal conteúdo das entrevistas. Mas foram as ações mais observadas nos corredores da escola e nas redes sociais dos envolvidos. Os registros são os mais variados possíveis: fotos dos momentos do lanche, selfies com os colegas, a ida a uma festa ou evento, a nova companhia, a roupa nova, até mesmo a foto da atividade no quadro branco ou do caderno com a agenda do dia, evitando ter que copiá-la manualmente.

Por outro lado, verificamos que os vídeos e imagens oriundos das propostas escolares não são, em regra, postados em suas páginas pessoais. Em alguns casos, quando foi solicitado aos estudantes que postassem estas fotos ou vídeos, eles criaram novos perfis, específicos para esta finalidade. Uma vez que as redes sociais pertencem ao universo dos estudantes, que delas se apropriam sem intenções formativas, compreendemos que, pode a escola, ajudar a reconfigurar os olhares destes estudantes, permitindo ver nestas redes virtuais, novas possibilidades de uso, com vistas ao próprio crescimento, às próprias aprendizagens, à formação e à emancipação.

Mais importante do que estar naquele espaço e lugar, para estes adolescentes parece ser, fazer um registro imagético. Uma reflexão importante é o como esta preocupação com os registros pode tirar destes adolescentes a possibilidade de experienciar a aura (BENJAMIN, 2017) daquele momento, o usufruir completo dos mais variados componentes daquele ambiente: cheiros, sons, cenários, registrando de tal forma aquela experiência em suas memórias, que estas seriam possivelmente mais duradouras e significativas. Esta consideração pode ser potencialmente relevante para a formação escolar, já que, a atenção destes jovens tem sido compartilhada com outros tantos estímulos alheios ao que está proposto naquele momento, através das TIDC, reduzindo o seu potencial de elaboração.

Algumas práticas de ordem mais pessoal, religiosas, esportivas ou outras, são também objeto de fotografias e vídeos para as redes sociais destes alunos, embora em menor escala do que as selfies e outras fotos não temáticas. Como exemplos, durante as entrevistas, algumas falas dos adolescentes retratam esta diversidade de postagens no Instagram:

- (Eu posto) foto minha, resultado de jogos, essas coisas (Guilherme ${ }^{5}, \mathrm{c}$ celular $\left.{ }^{6}\right)$.

- Eu gosto bastante de ver alguns... pregadores mirim, que eles postam vários vídeos de pregação... Eles postam um bocado de coisa, bastante interessante. Até, tem vez que textos, assim que eles escrevem, sobre depressão, eu sempre publico, lá nos meus stories, que é sempre bom pro jovem, pro grupo jovem, tá lendo, entendeu? E refletindo algumas coisas... Eu posto fotos também, mas as fotos que eu tiro, eu não posto muito. Eu gosto mais de postar sobre, tipo a igreja, entendeu? Sobre a religião. Não gosto muito de postar foto. Mas eu posto foto sim (Marta, c/ celular).

\footnotetext{
${ }^{5}$ Por questões éticas, foram atribuídos nomes fictícios aos estudantes que participaram desta pesquisa.

${ }^{6}$ Os termos “c/ celular" e "s/ celular" referem-se a respectivamente a possuir ou não o smartphone.
} 
Também não esteve presente nas falas dos estudantes, durante as entrevistas, qualquer uso de redes sociais ou demanda comunicacional que partisse dos professores da escola. Entretanto, vários são os alunos que se valem das redes sociais para manter comunicação referente às questões escolares. A mais evidente delas, diz respeito a manter um grupo de WhatsApp, por sala de aula, em que todos podiam compartilhar conteúdos e obrigações escolares, tornando-as disponíveis e acessíveis a todos, de modo a não haver esquecimentos, uma espécie de diário virtual. Abaixo, transcrevemos algumas destas falas:

- Tenho, tenho algumas redes sociais que eu uso no dia a dia, até pra comunicar com meus colegas sobre atividades, pesquisas, estas coisas. WhatsApp, tem grupo da escola [...] que a gente, quando tem atividade, data de prova, teste... (Arthur, s/ celular).

- Tipo, eu faltei no dia, eu vou lá e pergunto à algum amigo o que a professora deu. Tem um grupo da gente também que eu vou lá e pergunto... no Face e no WhatsApp (Guilherme, c/ celular).

- E também tem o grupo do colégio, da sala. De pesquisa da sala. Que sempre tem informações das aulas, quando a gente não vai, tem informação que, sempre tem uma pessoa que vem pro colégio, coloca lá no grupo pra gente saber, ficar por dentro (Matheus, c/ celular).

Um deles, quando perguntado especificamente como era essa comunicação escolar, respondeu:

- Pra conversar... pegar... quando eu faltava, pegar as atividades... (Thomas, s/ celular)

Durante as intervenções nas aulas de Educação Física, os alunos eram convidados a fazer uso de recursos cada vez mais diversificados em seus celulares enquanto aprendiam sobre o voleibol: câmera de foto e vídeo, calculadora, bloco de notas, navegador de internet, aplicativos com finalidade de edição, redes sociais, armazenamento de arquivos, dentre outros. Nossa intenção foi reeditar os olhares sobre estes recursos, habilitando-os à aprendizagem, à formação.

Particularmente com relação às redes sociais, observamos e registramos a utilização do WhatsApp e Instagram para comunicação e postagem das experiências durante a unidade didática. Contudo, o conteúdo das aulas não fazia parte das postagens dos alunos em suas páginas virtuais pessoais e sim, em outras criadas especificamente para as postagens escolares, reforçando o já observado distanciamento entre a vida intra e extra escolar para estes alunos, outro fator que merece maior aprofundamento. $\mathrm{O}$ conteúdo pedagogizado é desinteressante quando considerado o principal objetivo das postagens nas redes sociais: as curtidas? Qual o principal motivo para o distanciamento estabelecido pelos alunos entre sua vida escolar e privada? Por que alguns alunos, ao postarem conteúdos referentes às aulas, criam uma nova página em vez de publicarem em suas páginas pessoais?

Além disso, identificamos durante as entrevistas que os alunos se valiam de suas redes sociais como percursos para suas leituras. Eis algumas manifestações dos estudantes:

\footnotetext{
- De vez em quando, alguns livros que eu tenho que baixar, tem aplicativos que, pessoas podem até escrever livros que ai se eu não tiver encontrando, alguma coisa, vou lá no aplicativo e vejo, whattpad. É um aplicativo onde você pode ler livros e escrever também. Já baixei livro sobre ficção científica lá (Arthur, c/ celular).
} 
- Ah... tem livro. Porque... como o pastor manda a gente saber bem sobre as religiões, sobre os negócios assim de demônio, pra gente ficar mais atento, aí tem um livro que é... "cablocos e orixás", que eu assisto... é... leio, pela internet... eu baixei pelo... "ô jesus, como é o nome..." quer dizer, a missionária me enviou o link, e aí, eu peguei e baixei... pelo google, foi (Marta, c/ celular).

- Eu antes eu lia os livros das minhas amigas, porque antes eu tinha um aplicativo que, elas quando eu tava com celular, elas... tinha um aplicativo que elas próprio produziam os livro delas e eu lia [...] já escreveram vários livros com vários capítulos, era duas juntas que, escreviam as notícias de... várias histórias, sobre romance, terror, suspense, várias histórias... (Bianca, s/ celular).

- Leio um livro eletrônico. Leio dois..., três na realidade. Um é "O diário de um suicida". Leio é... "Um psicopata e um suicida" e leio "Meu amigo Espírito Santo" (Débora, c/ celular).

- Li "O diário de um banana", do dois até o sete e..., "O pequeno príncipe", no google biblioteca.

Por estas falas, podemos depreender que eles têm encontrado vias alternativas para suas leituras, de base digital, através das redes sociais. Martín-Barbero (2014) acredita que parte significativa do mundo adulto, de modo particular o acadêmico, atribui aos meios audiovisuais a causa da crise da leitura e do empobrecimento cultural, acreditando poder encontrar nos livros a salvação para o que ele chama de "[...] nova barbárie midiática" (p. 15). Neste caso, o abandono das formas físicas de leitura não necessariamente se traduz em equivalente perda de leitores. Por outro lado, para Amendola, Gigli e Monti (2018), a migração dos suportes de leitura do impresso ao digital como as mensagens do tipo SMS, tweet e outras, pode privilegiar o uso superficial da linguagem, muito simples e essencial, com prejuízos aos argumentos e ao aprofundamento. É papel da escola, identificar estas dinâmicas, elencando estratégias que deem respostas adequadas a questões como esta.

Contraditoriamente, as redes sociais digitais, presentes nas vidas de nove em cada dez estudantes, não são matéria-prima para ações educativas que emanem da própria escola. Identificar e problematizar o que tem sido postado e o que tem sido suprimido, as linguagens utilizadas, recursos mais utilizados, dentre outros aspectos, podem ser ponto de partida para o ato formativo.

Avançamos nos questionamentos e identificamos que também nove em cada dez, são os estudantes que acessam o Youtube. Durante um acesso qualquer nesta plataforma, é possível ver a influência das publicidades em meio aos vídeos que efetivamente são procurados. Além do mais, para cada vídeo assistido, o Youtube te oferece outras opções de vídeos similares ou mesmo diferentes, abrindo precedente para uma navegação perigosa e com conteúdo que pode ser impróprio para determinado público. Compreendemos mais uma vez, o quão necessário e urgente é a abordagem mídia-educativa, permeando os diversos componentes curriculares ou em outros formatos, como projetos pontuais, sobretudo tomando em consideração sua dimensão crítica, no sentido de formar para os potenciais riscos destas e de outras redes sociais. Estes riscos são potencializados quando verificamos neste estudo que, pouco mais da metade dos seus pais exercem algum tipo de gerenciamento sobre o uso do dispositivo. Se considerarmos a migração dos adolescentes para as redes sociais onde os adultos estão menos presentes, conforme apontam Amendola, Gigli e Monti (2018), estes estudantes podem estar transitando por vias com eminentes riscos à sua formação.

Durante as vivências do voleibol propriamente dito, as aprendizagens práticas foram conduzidas principalmente por meio de jogos com regras e espaços adaptados, evitando filas para repetição dos gestos do jogo, como na abordagem analítica. Através 
do uso dos jogos, quantidades maiores de alunos participavam por mais tempo, além da motivação de já estarem jogando voleibol desde o princípio. Assim, os alunos que já possuíam algum domínio do esporte, questionavam o fato de a bola poder tocar no chão, de poder se dar mais de três toques na bola, de pegá-la do "jeito errado" etc. Aqui apareciam as primeiras representações de um voleibol midiático, fechado, que não abria possibilidade para outras formas de se jogar esta modalidade. Importante dizer que o voleibol midiático, via de regra, não tematiza as diferentes possibilidades de experimentação esportiva, portanto, o que se constrói nos imaginários neste caso, é tão somente o voleibol competitivo, oficial, veiculado nas mídias, disputados nos campeonatos no Brasil e no mundo.

Pires (2002) é um dos autores que trata das representações esportivas construídas através das mídias e que, através delas, os sujeitos passam a conceber um tal modelo de esporte, que fundamenta sua concepção destas modalidades. Uma vez que a produção destes conteúdos possui objetivos claramente definidos, de vender um espetáculo lucrativo, agregando valor ao máximo de elementos possível que possa ser atrelado a cada veiculação, podemos antecipar que ideologias, valores e crenças, são construídos como pano de fundo e que, sem o devido olhar crítico, acabam sendo estas as representações que explicam o modelo de esporte em que a sociedade, de modo geral, conhece e acredita. Outras possibilidades, menos rentáveis, são excluídas das mídias, principal meio de acesso ao conhecimento esportivo e a outros elementos da cultura corporal, mesmo que em menor escala.

Continuando com a prática do voleibol, como ilustração de algumas das propostas de ensino, citamos a vivência do saque. Nos moldes do voleibol oficial, os jogadores são distribuídos na quadra de jogo em posições numeradas de um a seis, garantindo uma determinada lógica de ocupação do espaço de jogo e o saque é realizado sempre pelo jogador da posição número um, que enquanto detentor do saque, deve continuar sacando indefinidamente. Em nossa proposta, os alunos deveriam realizar o rodízio a cada novo saque. Esta reconfiguração de jogo permitiu que eles aprendessem no contexto do jogo, não somente o rodízio, como ampliavam a quantidade de vezes que experimentavam o saque e garantia a todos oportunidades semelhantes de prática. Outra diferença significativa é que, ao realizar o rodízio e chegar à posição número um, o jogador que fosse sacar, poderia se posicionar em qualquer lugar da quadra, aproximando-se gradativamente da linha de fundo, como no jogo oficial, mas somente quando assim decidisse. Novas manifestações por parte dos alunos, sobretudo aqueles que se apropriavam dos fundamentos deste esporte. Segundo eles, "aquele voleibol inventado" não era voleibol. Falas desta natureza foram matéria-prima para as discussões em diferentes momentos da aula, na busca por realizar a crítica a respeito destas concepções, configurando ainda a dimensão crítica da abordagem mídia-educativa (FANTIN; RIVOLTELLA, 2012).

Em seguida, uma das etapas previstas seria a produção de um pequeno vídeo, com no mínimo um e no máximo cinco minutos de duração, em que cada equipe deveria tratar da condição da quadra da escola. Para Fantin e Rivoltella (2012) a abordagem mídia-educativa é definida como uma educação que é feita "com", "para" e "através" das mídias. Deste modo, a produção midiática demandada nesta ação formativa, esteve consoante com a dimensão produtiva desta abordagem, ou educação "através" das mídias. A educação para a mídia, segundo esta autora, diz respeito à apropriação crítica dos conteúdos midiáticos, enquanto educar com estas seria o seu uso como instrumento didático. Portanto, estivemos atentos a esta premissa como eixo da proposta formativa contemplando as TDIC nestas três dimensões. 
Apesar das orientações para que os conteúdos das produções tratassem das vivências e construções da unidade didática, a maior parte dos trabalhos versou sobre a história do voleibol no Brasil, a biografia de algum jogador de destaque, fundamentos do voleibol e sobre o próprio jogo, não nos moldes das experiências da escola, mas dos conteúdos que estão mais disponíveis na mídia. É possível que a disponibilidade do conteúdo pronto e formatado na internet, tenha levado os alunos a cópias e colagens deste material, rompendo com a proposta apresentada. Este é um dos riscos das tecnologias digitais, o abandono da criatividade e da produção, através da possibilidade trazida pela reprodutibilidade técnica.

Analisando as entrevistas, identificamos ainda o quanto o termo esporte é utilizado como substitutivo do termo Educação Física. Podemos imaginar que as aulas nesta escola são fortemente pautadas com o conteúdo esporte e adicionalmente, podemos inferir que, uma vez que as práticas corporais presentes nas mídias são majoritariamente relacionadas ao conteúdo esportivo, esta seja uma das formas pelas quais os estudantes constroem representações a respeito das aulas de Educação Física enquanto sinônimo de esportes. Com a mesma gravidade, o esporte que é compreendido pelos alunos, ficou tácito nas aulas, é o esporte federativo, de alto rendimento, com regras rígidas e movimentos específicos.

Assim, vimos que o acesso ao conteúdo midiático das redes sociais através do celular é multifacetado e vai desde a simples curiosidade com o que é postado nas diversas páginas dos diversos relacionamentos que os estudantes estabelecem, até a aprendizagem de músicas, danças, culinária, idiomas etc. No que concerne à Educação Física, percebeu-se o quanto as mídias podem distorcer a compreensão dos estudantes da educação básica a seu respeito. O precedente aqui é valioso para o meio educacional pelos motivos já expostos, tornando-se imperativo problematizar, criticar estas aprendizagens espontâneas no sentido de torná-las significativas do ponto de vista formativo.

\section{CONCLUSÕES}

As tecnologias digitais de informação e comunicação, de modo particular o celular smartphone conectado à internet, são os principais meios de acesso à informação da atualidade. Verificou-se que $97 \%$ dos brasileiros buscam informações na rede de internet através deste dispositivo, sobretudo nas chamadas redes sociais virtuais, onde está grande parte do acervo de informações disponíveis hoje. De singular relevância a este estudo, estiveram as possíveis representações que estudantes da educação básica podem construir a respeito dos elementos da cultura corporal de movimento, com base nas informações fragmentadas obtidas nestas redes, o que foi verificado em diversos momentos. Durante as aulas de Educação Física realizadas ao longo deste estudo, foi abordado o conteúdo voleibol. Nas atitudes e nas falas dos estudantes era marcante a presença de um modelo de voleibol que foi instituído antes mesmo do tratamento pedagógico do voleibol na escola. $\mathrm{O}$ voleibol de alto rendimento, com regras rígidas e modos fechados de experimentação, comumente presente nas mídias. Adicionalmente, a Educação Física era comumente tratada pelos estudantes como sinônimo de esporte, encontrando nas mídias um dos motivos para esta representação.

Este breve olhar sobre os usos e apropriações das redes sociais virtuais pelos estudantes da educação básica, no contexto da Educação Física já permite afirmar que, as proposições, discussões e a reflexões desta realidade é parte de uma atuação docente 
comprometida com a leitura de mundo e independe do aparato tecnológico digital da escola.

É possível propor, buscar, participar de formações continuadas no âmbito das tecnologias, construindo inclusive no fazer docente, saberes que comporão uma crescente competência com as TDIC. Trazer para as discussões de sala de aula as músicas, vídeos, postagens oriundas de redes sociais e outros conteúdos midiáticos que já são apropriadas pelos estudantes. Aproximar os pais destas discussões, propor grupos de estudos, oficinas e outras estratégias que possam reduzir a lacuna que hoje se instala na maior parte das escolas sobre esta temática, são possíveis passos iniciais.

Conclui-se que, através da abordagem mídia-educativa, é possível propor resistência às construções fragmentadas propostas pelas mídias, particularmente pelas redes sociais virtuais, partindo da reflexão dos panos de fundo dos seus conteúdos, buscando edificar saberes próprios, significativos e contextualizados no sentido da formação emancipatória no contexto da Educação Física.

\section{REFERÊNCIAS}

ADORNO, T. W. Indústria cultural e sociedade. São Paulo: Paz e Terra, 2002.

ADORNO, T. W. Educação e emancipação. Rio de Janeiro: Paz e Terra, 1995.

AMENDOLA, A.; GIGLI, B.; MONTI. A. M. Adolescenti nella rete. Quando il web diventa uma trappola. Roma: L'Asino d'oro, 2018.

BENJAMIN, W. A obra de arte na era de sua reprodutibilidade técnica. Porto Alegre: L\&PM, 2017.

DIAS, C.; COUTO, O. F. As redes sociais na divulgação e formação do sujeito do conhecimento: compartilhamento e produção através da circulação de ideias. Linguagem em (Dis)curso, v. 11, n. 3, p. 631-648, set./dez. 2011. Disponível em: https://www.scielo.br/pdf/ld/v11n3/a09v11n3. Acesso em: 05 jul. 2020.

FANTIN, M.; RIVOLTEllA, P. C. (orgs.). Cultura digital e escola: pesquisa e formação de professores. Campinas: Papirus, 2012.

GIMENO SACRISTÁN, J.; PÉREZ GÓMEZ, A. I. Compreender e transformar o ensino. Porto Alegre: Artmed, 1998.

IBGE. Pesquisa nacional por amostra de domicílios. Equipamentos de acesso a internet por domicílio. Pesquisa $\quad$ suplementar $2017 . \quad$ Disponível em: ftp://ftp.ibge.gov.br/Trabalho_e Rendimento/Pesquisa_Nacional_por_Amostra de Domicilios continua/ Anual/Acesso_Internet Televisao e Posse Telefone Movel_2017/PNAD_Continua_2017 TIC tabelas domicilios xls.zip. Acesso em: 05 jul. 2020.

MARTÍN-BARBERO, J. A comunicação na educação. São Paulo: Contexto, 2014.

MILLS, C. W. A imaginação sociológica. Rio de Janeiro: Zahar, 1972.

MINAYO, M. C. S. O desafio do conhecimento: pesquisa qualitativa em saúde. 14. ed. São Paulo: Hucitec, 2014.

MINAYO, M. C. S. Pesquisa social: teoria, método e criatividade. Petrópolis: Vozes, 2016.

MUlleR, J. C. Crianças e tecnologias digitais: desafios da mediação familiar e escolar. 2019. Tese (Doutorado em Educação) - Centro de Ciências da Educação, Universidade Federal de Santa Catarina, Florianópolis, 2019. Disponível em: 
https://repositorio.ufsc.br/bitstream/handle/123456789/204487/PEED1418-T.pdf?sequence=1\&isAllowed=y. Acesso em: 10 jul. 2020.

PIRES, G.L. Educação física e o discurso midiático: abordagem crítico-emancipatória. Ijuí: Ed. Unijuí, 2002.

PUCCI, B.; COSTA, B. C. G.; CAMPOS, N. M. A. S. A.; SILVA, L. B. O. (org.). Atualidade da teoria crítica na era global. São Paulo: Nankim, 2016.

RECUERO, R. Redes sociais na internet. 2. ed. Porto Alegre: Sulina, 2018.

SOARES, C. L.; TAFFAREL, C. N. Z.; VARJAL, E.; CASTELLANI FILHO, L.; ESCOBAR, M. O., BRACHT, V. Metodologia do ensino da educação física. 2. ed. rev. São Paulo: Cortez, 2009.

SOUSA, G.R.; MENDES, D.S. Mídias na formação em educação física: análise de uma disciplina optativa. Revista Motrivivência, v. 26, n. 43, p. 300-315, dez. 2014. Disponível em: https://periodicos.ufsc.br/index.php/motrivivencia/article/view/2175-8042.2014v26n43p300/28126. Acesso em: 05 mai. 2020.

TÜRCKE, C. Sociedade excitada: filosofia da sensação. Campinas: Editora da Unicamp, 2010.

Recebido em: 11 jul. 2020.

Aprovado em: 29 ago. 2020. 